\title{
Surface Hardening Alloy VT6 of Electric Explosion and by Electron Beam
}

\author{
Yu. F. Ivanov ${ }^{1, \text { a) }}$, T. Yu. Kobzareva ${ }^{2, b)}$, S. V. Raikov ${ }^{3, c)}$, V. E. Gromov ${ }^{2, b)}$, \\ N. A. Soskova ${ }^{2, \text { b) }}$, and E. A. Budovskikh ${ }^{2, d)}$ \\ ${ }^{1}$ High Current Electronics Institute SB RAS, Tomsk, 634055, Russia \\ ${ }^{2}$ Siberian State Industrial University, Novokuznetsk, 654007, Russia \\ ${ }^{3}$ Tomsk National Research Polytechnic University, Tomsk, 634050, Russia \\ a)yuf155@mail.ru \\ b) Corresponding author: gromov@physics.sibsiu.ru \\ c) vest2002@mail.ru \\ d) budovskih_ea@physics.sibsiu.ru
}

\begin{abstract}
The aim is to study the phase composition, structure and properties of the surface layer of the VT6 titanium alloy, subjected to combined treatment, consisting of alloying by the plasma of an electric explosion of a graphite fiber with a charge of the $\mathrm{SiC}$ powder and subsequent exposure by a high-intense electron beam. As a result of such treatment, a multiphase surface layer with a submicron and nanosize structure forms with the microhardness manifold exceeding its value in the sample volume are presented.
\end{abstract}

Keywords: electron-beam treatment, structural-phase states, electric explosion alloying, titanium, scanning and transmission electron microscopy

\section{INTRODUCTION}

Titanium and titanium-based alloys are the most in-demand structural materials [1] and various coatings are used for the surface protection of made of them wares [2,3]. One of the most promising methods of forming coatings is electric explosion alloying $[4,5]$. Properties of the surface layer of the material and the ware are additionally improved as a whole after combined treatment uniting the electric explosion alloying and the subsequent electronbeam treatment of the modified surface $[5,6]$.

The electron-beam treatment has more possibilities for the control and regulation of supplied energy when compared with widespread laser technology. This method is characterized by the local energy distribution in the surface layer of the treated material and high efficiency [7]. Therefore, substantial changes in the structural-phase state of surface layers lead to a significant improvement in physicochemical and strength properties of the material that are unattainable for traditional methods of surface treatment.

\section{MATERIAL AND PROCEDURE OF STUDY}

As the modified material we selected VT6 titanium alloy with the composition, wt. $\%, \leq 0.6 \mathrm{Fe}, \leq 0.1 \mathrm{C}, \leq 0.1 \mathrm{Si}$, 3.5-5.3 V, 5.3-6.8 Al, $\leq 0.3 \mathrm{Zr}, \leq 0.05 \mathrm{~N}, \leq 0.2 \mathrm{O}, \leq 0.015 \mathrm{H}$; the remainder is Ti, which is applied for the production of the large-size welded and built-up structures of aircrafts and for the manufacture of vessels operating under the internal pressure in a wide temperature range and a whole series of other structural elements related by the structure to the class of $(\alpha+\beta)$ alloys [9]. The samples were washer-shaped $10 \mathrm{~mm}$ thick and $18 \mathrm{~mm}$ in diameter.

International Conference on Physical Mesomechanics of Multilevel Systems 2014 AIP Conf. Proc. 1623, 217-220 (2014); doi: 10.1063/1.4901482

(C) 2014 AIP Publishing LLC 978-0-7354-1260-6/\$30.00 


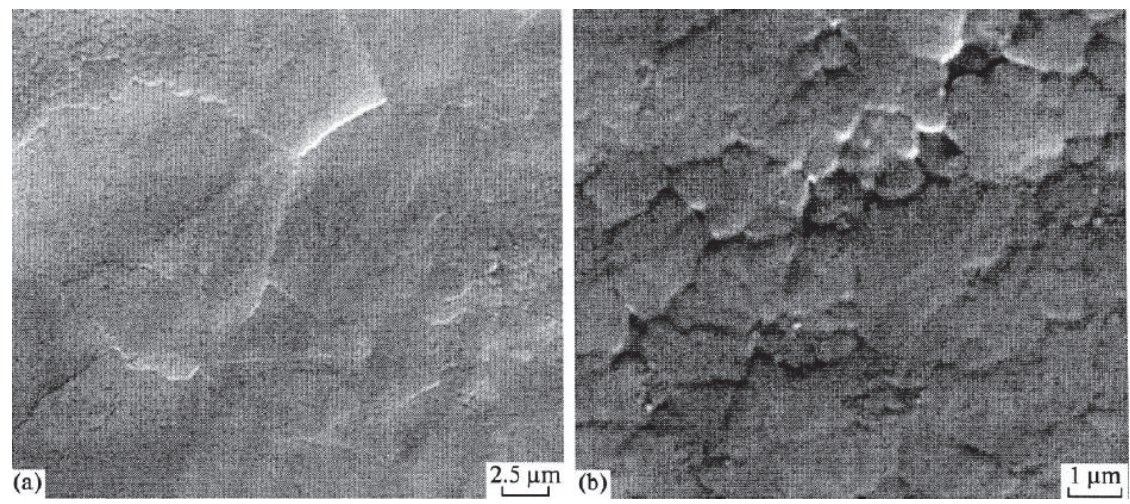

FIGURE 1. Electron microscopic image of the surface structure after electric explosion alloying $(\mathrm{CF}+\mathrm{SiC})$ and further electronbeam treatment (scanning electron microscopy). $E_{\mathrm{s}}=45 \mathrm{~J} / \mathrm{cm}^{2}, \tau=100 \mu \mathrm{s}, z=10 \mu \mathrm{m}$ and $f=0.3 \mathrm{~s}^{-1}$

The doping of the surface layer was implemented by the action of plasma formed during the electric explosion of carbon fibers $(\mathrm{CF})$ with the charge of silicon carbide $(\mathrm{SiC})$ powder placed on its surface in the explosion area. The electric explosion alloying mode was as follows: the absorbed power density was $6.5 \mathrm{GW} / \mathrm{m}^{2}$, the diameter of the accelerator nozzle was $20 \mathrm{~mm}$, the sample distance from the nozzle cut was $20 \mathrm{~mm}$, the weight of carbon fibers was $140 \mathrm{mg}$, and the powder weight was $50 \mathrm{mg}$. These conditions correspond to an average thickness of the molten layer of $30 \mu \mathrm{m}$ in $[5,6]$.

The additional treatment of the modified layer was implemented by a high-intense electron beam on a SOLO installation [10] according to the following modes: electron energy of $18 \mathrm{keV}$, electron beam energy density $E_{\mathrm{s}}=45-60 \mathrm{~J} / \mathrm{cm}^{2}$, action pulse duration $T=100$ and $200 \mu \mathrm{s}$, pulse number $n=10$ and 20 , and pulse repetition frequency $f=0.3 \mathrm{~s}^{-1}$; the exposure was performed in argon at residual pressure of $0.02 \mathrm{~Pa}$.

Investigations into the elemental and phase compositions and the granular and intragranular structures of the surface layer were carried out by scanning and electron diffraction microscopies $[11,12]$ and X-ray structural analysis (the Bragg-Brentano geometry and $\mathrm{CoK}_{\alpha}$ radiation). The mechanical properties of the surface layer were evaluated by microhardness measurements.

The surface layer formed after electric explosion alloying, similarly to earlier investigations [5, 6], is characterized by a high level of roughness and a great variety of structural elements (micropores and microcraters, microcracks, buildups, and particles of loosened graphite fibers).

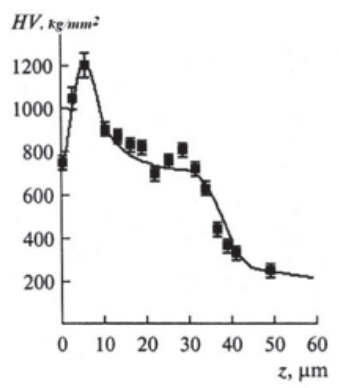

(a)

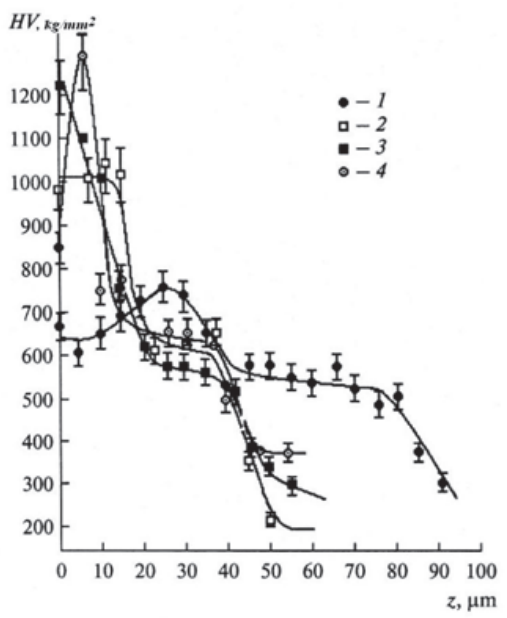

(b)

FIGURE 2. Microhardness distribution over the depth after electric explosion alloying (a) and electron-beam treatment in modes $1-4$ (b) 
TABLE 1

\begin{tabular}{ccccc}
\hline Mode & $\boldsymbol{E}_{\mathbf{s}}, \mathbf{J} / \mathbf{c m}^{\mathbf{2}}$ & $\boldsymbol{\tau}, \boldsymbol{\mu s}$ & $\boldsymbol{N}$, pulse & $\boldsymbol{f}, \mathbf{s}^{-\mathbf{1}}$ \\
\hline 1 & 45 & 100 & 10 & 0.3 \\
\hline 2 & 50 & 100 & 10 & 0.3 \\
\hline 3 & 60 & 100 & 10 & 0.3 \\
\hline 4 & 45 & 200 & 20 & 0.3
\end{tabular}

\section{RESULTS OF STUDY AND DISCUSSION}

The further electron-beam treatment is accompanied by a substantial decrease in its roughness (Fig. 1(a)). A polycrystalline structure with grains $10 \mu \mathrm{m}$ in size is revealed on the surface. A subgranular structure (cells with high-rate crystallization) is observed in the grain volume with the subgrain size in a range of $0.2-0.8 \mu \mathrm{m}$ (Fig. 1(b)).

Melting of the surface layer by the electron beam and the further high-rate crystallization lead to the formation of a multilayer structure presented by the doped layer proper and the layer of the thermal effect, which gradually propagates into the main volume of the material. The thickness of the doped layer is almost independent of the electron-beam treatment mode and varies in a range from 25 to $30 \mu \mathrm{m}$. This layer in depth divides into three clearly pronounced sublayers that we call surface, near-surface and intermediate layers differing in morphology and sizes of the structural elements at an electron beam energy density of 45 and $50 \mathrm{~J} / \mathrm{cm}^{2}$ and action pulse duration of $100 \mu \mathrm{s}$. For example, the doping layer preliminary has a globular structure. During treatment with $E_{\mathrm{s}}=60 \mathrm{~J} / \mathrm{cm}^{2}$ and $\tau=100 \mu \mathrm{s}$, as well as $E_{\mathrm{s}}=45 \mathrm{~J} / \mathrm{cm}^{2}$ and $\tau=200 \mu \mathrm{s}$, its structure improves and does not divide into sublayers.

$\mathrm{X}$-ray phase analysis of the exposure surface showed that the strengthening zone contains second phases along with $\alpha-\mathrm{Ti}$, the volume fraction of which varies in from $30 \%$ to $50 \%$; titanium carbide (TiC) is basic among them.

An analysis of the strength characteristics of the VT6 alloy surface layer, which is based on the construction of the microhardness profile, shows that the maximum of $H V$ after the electric explosion alloying is reached in 10- to 12- $\mu \mathrm{m}$-thick near-surface layer (Fig. 2(a)) and exceeds this value for the base by a factor of 3.5-5.5. The thickness of the surface layer with microhardness threefold greater than for the base reaches $35 \mu \mathrm{m}$. Further electron-beam treatment leads to a substantial increase in its value to $85-90 \mu \mathrm{m}$ (see Fig. 2(b)).

To elucidate the physical nature of an increase in the microhardness of the doped layer, we analyzed foils placed near the treatment surface $(2-3 \mu \mathrm{m})$ and at a depth of $25 \mu \mathrm{m}$ by transmission electron microscopy after electric explosion alloying and electron-beam treatment by mode 3 (see the Table 1). The structure of these layers, which was determined by scanning electron microscopy of the metallographic cross section, is represented in Fig. 3(a). Figure 3(b) shows the distribution of silicon in the doped layer, which was revealed by electron probe microanalysis. It is clearly seen that the concentration of $\mathrm{Si}$ at the doping surface is $8-10 \mathrm{wt} . \%$ and, being monotonically decreased, terminates at the boundary with the thermal influence layer.
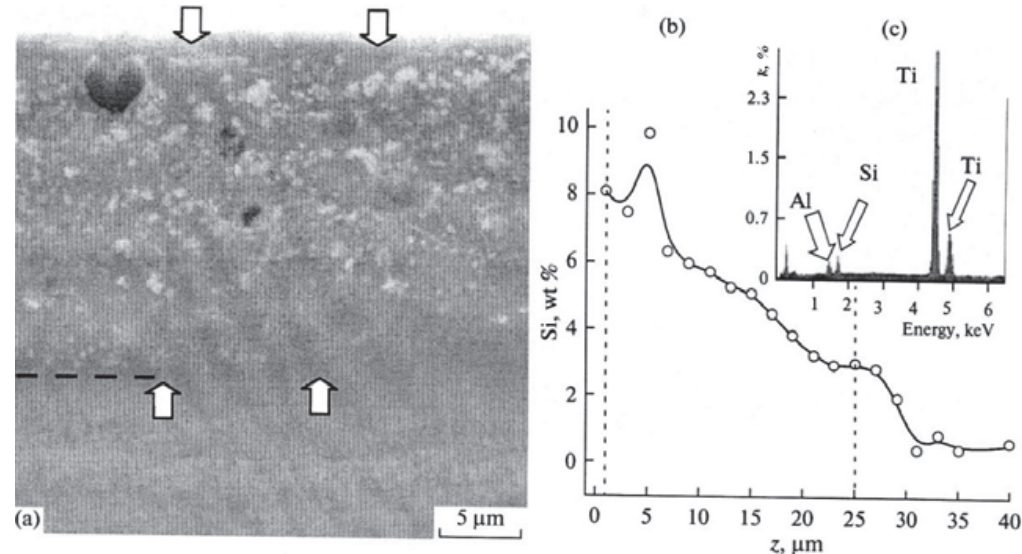

FIGURE 3. Gradient structure over the structure depth and the elemental composition of the combined treatment zone of the VT6 alloy surface. Picture (a) shows the layers, which were investigated by transmission electron microscopy 
The subgrain volume reveals a lamellar substructure of $\alpha$-Ti in the subgrain volume; its plate thickness varies in a range from 50 to $150 \mu \mathrm{m}$. Particles of the second phase are placed in the form of extended inter-layers or globules, which are arranged along subgrain boundaries and in boundary junctions. These particles are titanium (TiC) and silicon $(\mathrm{SiC})$ carbides according to data of diffraction microanalysis. The $\mathrm{SiC}$ particles are globular-shaped and their sizes vary in a range from 50 up to $100 \mathrm{~nm}$.

Thus, a multiple increase in the microhardness of the strengthening zone of the VT6 alloy after combined treatment is caused by the formation of a multiphase submicron and nanosize lamellar structure based on $\alpha$-Ti, which is reinforced by particles of titanium and silicon carbides.

A structure similar to abovementioned one also forms in the layer placed at a depth of $25 \mu \mathrm{m}$; notably, a granular-subgranular structure with subgrains $350 \mu \mathrm{m}$ in size on average manifests itself. A lamellar substructure is revealed in their volume ( $\alpha$-Ti; plate thickness varies in a range from 40 to $80 \mathrm{~nm}$ ). Sub-grains are divided by extended interlayers of the second phase (plate thickness varies in a range from 40 up to $80 \mathrm{~nm}$ ). The diffraction microanalysis of the structure of this layer revealed strong diffuse scattering in electron diffraction micropatterns, which indicates the lamination of the $\alpha$-Ti-based solid solution, a high imperfection level of the crystal lattice of $\alpha$ $\mathrm{Ti}$, and the destruction of the long-range order [12].

\section{CONCLUSIONS}

The electric explosion carbonization jointly with particles of the $\mathrm{SiC}$ powder forms a strengthened layer $35 \mu \mathrm{m}$ thick on the surface of the VT6 alloy with the microhardness exceeding the same of the base by a factor of 3-5. Further electron-beam treatment decreases the roughness of the modified surface and leads to an increase in the thickness of the strengthened layer to $85-90 \mathrm{~m} \mu$.

A multiple increase in the microhardness of the surface layer of the VT6 alloy subjected to electric explosion alloying and further electron-beam treatment is caused by the formation of the multiphase submicron and nano-size lamellar structure based on $\alpha-\mathrm{Ti}$, which is strengthened by the nanosize precipitates of second phases of $\mathrm{TiC}$ and $\mathrm{SiC}$.

This work was supported in part by the Russian Foundation for Basic Research (Scientific Project No. 13-0212009 ofi_m) and by the Ministry of Education and Science of the Russian Federation (State Assignment No. 2708).

\section{REFERENCES}

1. Ya. Polmear, Light Alloys: from Traditional to Nanocrystals (Tekhnosfera, Moscow, 2008).

2. G. V. Bobrov and A. A. Il'in, Application of Innorganic Coatings. Theory. Technology. Equipment: Tutorial for Higher School (Intermet Inzhiniring, Moscow, 2004).

3. M. Hocking, V. Vasantasree, and P. Sidky, Metallic and Ceramic Coatings: Production, High Temperature Properties and Applications (Longman, Essex, 1989).

4. A. Ya. Bagautdinov, E. A. Budovskikh, Yu. F Ivanov, et al., Physical Fundamentals of Electric Explosion Alloying of Metals and Alloys (Sib. State Industr. Univ, Novokuznetsk, 2007).

5. S. V. Karpii, M. M. Morozov, Yu. F. Ivanov, and V. E. Gromov, Structure, Phase Composition, and Properties of Titanium after Electric Explosion Alloying and Electron Beam Treatment (Scientific Production Complex, Novokuznetsk, 2010).

6. V. E. Gromov, Formation of Structural-Phase State of Metals and Alloys at Electric Explosion Doping and Electron Beam Treatment (InterKuzbass Publ. House, Novokuznetsk, 2011).

7. V. Rotshtein, Yu. Ivanov, and A. Markov, in Materials Surface Processing by Directed Energy Techniques, edited by Y. Pauleau (Elsevier, Oxford, 2006), p. 205.

8. A. M. Glezer, V. E. Gromov, Yu. F Ivanov, et al., Nanomaterials: Structure, Properties, and Application (InterKuzbass Publ. House, Novokuznetsk, 2012).

9. A. A. Il'in, B. A. Kolachev, and I. S. Pol'kin, Titanium Alloys. Composition, Structure, and Properties (AllRussia Inst. Light Alloys-Russ. State Technol. Univ., Moscow, 2009).

10. Yu. F. Ivanov and N. N. Koval', Structure and Properties of Promising Metallic Materials, edited by A. I. Potekaev (Sci. Tech. Liter., Tomsk, 2007).

11. L. Engel and H. Klingele, Scanning Electron Microscopy: Fracture. A Handbook (Carl Hanser, Munich, 1982).

12. D. P. Woodruff and T. A. Delchar, Modem Techniques of Surface Science (Cambridge Univ., Cambridge, 1986). 